\title{
EAD: UM CAMINHO SEM VOLTA
}

\author{
Pamera Francieli Corrêa Pereira (UNIOESTE) ${ }^{1}$ \\ João Carlos Cattelan (UNIOESTE) ${ }^{2}$
}

\begin{abstract}
RESUMO: A EAD - Educação a Distância - tem conquistado um espaço considerável na pluralidade das áreas, segmentos intelectuais e técnico-profissionais da cibercultura. O presente artigo terá a Análise do Discurso de linha francesa como principal base teórica para empreender uma discussão sobre a tendência do ensino a distância no imbricamento com o sujeito dessa época e suas condições de produção no espaço virtual. A EAD promete permanecer e transformar o que se entende por aprender, incidindo no sujeito atravessado pelo discurso da era digital, ligeiramente afetado pelo modo de ser e agir on-line, ao passo que o ensino a distância propicia uma experiência de autonomia na busca pelo conhecimento, alavancando estratégias comerciais do ramo da educação por desconstruir modelos de ensino vistos até então. O que implica atentar é que a EAD é um caminho sem volta: ou os sujeitos se adaptam a ela, se apropriam dessa atual esfera de captação do saber, ou estarão à margem de uma tendência educacional.
\end{abstract}

PALAVRAS-CHAVE: EAD. Sujeito. Apropriação.

ABSTRACT: Distance Learning has gained considerable space in the plurality of areas, intellectual and technical-professional segments of cyberculture. This article will have the French Line Discourse Analysis as the main theoretical basis to undertake a discussion about the trend of distance learning in the overlap with the subject of this time and its conditions of production in the virtual space. Distance learning promises to remain and transform what is meant by learning, focusing on the subject crossed by the discourse of the digital age, slightly affected by the way of being and acting online, while distance learning provides an experience of autonomy in the search for knowledge, leveraging commercial strategies of the branch of education by deconstructing models of teaching seen so far. What it means to be attentive is that distance learning is a path with no return: either people adapt to it, so they appropriate this current sphere of knowledge capture, or they will be on the sidelines of an educational tendency.

KEYWORDS: Distance Learning. Subject. Appropriation.

\section{INTRODUÇÃO}

Em um mundo de tempo escasso e de competição acirrada, atrelado à necessidade de garantir a sobrevivência e dar conta das exigências de um mercado de trabalho cada vez mais mutante, foi preciso adequar a formação profissional a uma realidade onde ofertas e demandas culminaram na formatação da EAD - Educação a Distância. Tal modalidade de ensino é continuamente elaborada e reelaborada para garantir que sujeitos tenham acesso à profissionalização formal de maneira flexível e otimizada no universo da cibercultura ${ }^{3}$.

\footnotetext{
${ }^{1}$ Mestranda do Programa de Pós-Graduação em Letras da Universidade Estadual do Oeste do Paraná. E-mail: pamerapr@hotmail.com

2 Doutor em Linguística e Língua Portuguesa pela Universidade Estadual Paulista Júlio de Mesquita Filho. Docente do Programa de Pós-Graduação em Letras da Universidade Estadual do Oeste do Paraná. E-mail: jccattelan@gmail.com

${ }^{3}$ Quanto ao neologismo 'cibercultura', especifica aqui o conjunto de técnicas (materiais e intelectuais), de práticas, de atitudes, de modos de pensamento e de valores que se desenvolvem juntamente com o crescimento do ciberespaço. O termo [ciberespaço] especifica não apenas a infraestrutura material da comunicação digital, mas também o universo oceânico de informação que ela abriga, assim como os seres humanos que navegam e alimentam esse universo (LÉVY, 1999, p. 17).
} 
Diante do quadro de formação on-line, depara-se com um sujeito atravessado pela formação discursiva da internet, em condições de produção que oferecem fluidez nas ações. Neste ensejo, entende-se que é uma questão de moldar aquele que vai lançar mão de estratégias digitais para adentrar nas mais diversas áreas de conhecimento, pois, após dominar as especificidades que dizem respeito ao mundo virtual, o sujeito é atravessado por formações ideológicas que passarão a alocá-lo como usuário/aluno partícipe da rede, do mundo das conexões virtuais.

Naturalmente, prós e contras fazem parte da discussão quando a temática é ensino a distância. Todavia, elencar os pontos negativos da modalidade virtual meramente para criticar não se torna proveitoso, visto que não há como negar o seu progresso, buscar soluções para as fragilidades dessa modalidade de ensino é o mais sensato a praticar. Pois o ensino a distância aponta para o crescimento acelerado em consonância com a ascensão tecnológica. $\mathrm{Na}$ derradeira aparição da internet ao mundo que, hoje, se configura globalizado, conectar é o verbo da fruição democrática, pois, em um click, tem-se ao alcance de milhares de pessoas uma gama considerável de informações e conteúdos sobre todas as áreas do saber, tornando acessível o conhecimento já construído pela humanidade.

No mundo da internet, do crescimento frenético da tecnologia, percebe-se que o sujeito, desse meio, é aquele que aprende e reaprende a linguagem e os mecanismos virtuais, destacando-os como imprescindíveis para continuar vivendo, ou sobrevivendo, num cenário competitivo e mudanças instantâneas. Trata-se do sujeito assujeitado às formações discursivas de domínio virtual, atravessado pela ideologia do universo da cibercultura que reúne, cada vez mais, estabelecer relações na esfera do digital, desde as questões pessoais, de educação, de negócios até tudo aquilo que permeia o humano.

\section{EAD E O SUJEITO PARA A ANÁLISE DO DISCURSO}

Nova modalidade de ensino, novo sujeito? Para a Análise do Discurso, o sujeito é aquele que é assujeitado por uma formação discursiva e atravessado por uma ideologia. Desse modo, o sujeito fala a partir de uma posição social, de um lugar designado que ocupa na sociedade que, por sua vez, assume o discurso específico da formação a qual pertence, como se falasse em nome dela, dando evidências da ideologia que o alicerça em seu dizer.

Com isso, diante da nova modalidade de ensino a distância tem-se, sim, um novo sujeito no que diz respeito à nova filiação de formação discursiva, que, neste caso, é todo o arbítrio da EAD atravessando o sujeito com sua formatação e condições de produção virtuais. Ou seja, o sujeito está à mercê do que lhe é externo, mas o infunde e o torna em um sujeito que passa a dizer e construir sentidos a partir do saber específico, como é o caso da formação discursiva da $E A D$, objeto de estudo desse artigo.

O sujeito da EAD não surgiu independentemente dos acontecimentos históricos, nem tampouco fora da interação com a língua ou por desprezar sua subjetividade. O sujeito do mundo on-line nasceu com todas as implicações que formam um sujeito, com toda a complexidade que o fazem ser o sujeito da atualidade, e que o farão sujeito da posteridade. A língua, a história e a subjetividade humana que constroem o universo simbólico que circunda cada sujeito, intrínseca e externamente, concebem o ser humano em suas complexidades. A interação no mundo on-line perpassa a capacidade do ser humano em fundir-se nas suas complexidades constitutivas. Se, hoje, é possível estudar a distância é porque a cadeia de afetos (no que diz respeito a afetar e ser afetado) fruiu e frui na sociedade como um todo. Quanto ao sujeito, a menção que segue pode ajudar a compreender: 
SUJEITO: resultado da relação com a linguagem e a história, o sujeito do discurso não é totalmente livre, nem totalmente determinado por mecanismos exteriores. O sujeito é constituído a partir da relação com o outro, nunca sendo fonte única do sentido, tampouco elemento onde se origina o discurso. Como diz Leandro Ferreira (2000) ele estabelece uma relação ativa no interior de uma dada Formação Discursiva; assim como é determinado, ele também a afeta e determina em sua prática discursiva. Assim, a incompletude é uma propriedade do sujeito e a afirmação de sua identidade resultará da constante necessidade de completude (FERREIRA, 2001, p. 23).

Depreender que o sujeito é a decorrência língua/história/subjetividade torna mais tangível conhecer as bases que constituíram a identidade desse sujeito que anseia a completude inalcançável. Nesse viés de busca e tentativas de saciar-se e de bastar-se enquanto ser que vive, por tentar preencher o que não se pode preencher, numa ilusão de que é possível completar-se, é justamente o que tira o ser humano da inércia e o faz explorar a si e ao mundo. Ainda que a liberdade seja dirigida, isto é, toda a relação humana no que diz respeito a consigo mesmo, com outros sujeitos e com o mundo se dará no interior de uma formação discursiva e seus atravessamentos ideológicos, o sujeito constitui e é constituído.

A interpelação ideológica faz do sujeito um repetidor de discursos, de dizeres que ele tem a ilusão de lhe serem próprios, como se ele fosse a origem de seu discurso. Contudo, não é o discurso que pertence ao sujeito, é o sujeito que pertence ao discurso, e o seu dizer (o seu discurso) vem atravessado de ideologia, afetado por uma formação discursiva que emerge de uma posição social ocupada pelo sujeito, que o faz dizer o que diz, e que o permite dizer o que diz. Pêcheux concebe esse pressuposto da seguinte forma:

[...] o sujeito se constitui pelo "esquecimento" daquilo que o determina. Podemos agora precisar que a interpelação do indivíduo em sujeito de seu discurso se efetua pela identificação com a formação discursiva que o domina (isto é, na qual ele é constituído como sujeito): essa identificação, fundadora da unidade (imaginária) do sujeito, apoia-se no fato de que os elementos do interdiscurso [...] que constituem, no discurso do sujeito, os traços daquilo que o determina, são reinscritos no discurso do próprio sujeito (PÊCHEUX, 1995, p. 163)

O que faz o sujeito atual identificar-se com a formação discursiva da EAD? Isso ocorre pelo fato de que o sujeito está inserido no fluxo de um mundo globalizado, em que a relação humana tem se configurado aos preceitos e normas da internet, e o ritmo de vida tem provocado escassez de tempo. Sendo assim, o sujeito se inscreve nessa formação discursiva e passa a ser interpelado por ela - no que diz respeito aos conceitos que dominam o ensino a distância. Tendo em vista que ele se molda e fala a partir do imaginário da virtualidade em nome de um melhor aproveitamento de seu tempo, de maior flexibilidade no horário para estudar e mais oportunidades. Nessa linha de raciocínio, é possível depreender que educação a distância tem contribuído para viabilizar aos sujeitos uma formação profissional que os tornem aptos a competir num mercado de trabalho voraz.

Pertencer à formação discursiva da era digital é atrelar-se ao combo de possibilidades nos espaços virtuais. Isso faz com que haja uma vida (relações humanas) acontecendo na esfera virtual, com seus sujeitos em modo "avatar" (analogia para compreender que é preciso criar e manter um perfil/personagem na rede para ser e agir nesse universo). Portanto, para adentrar e manter-se nesse imaginário discursivo da internet, é preciso aprender a língua e os discursos que fluem nesse meio. Ou seja, o sujeito atual está fadado à formação discursiva da internet para interagir com o mundo que o circunda, pois para manter-se como partícipe na sociedade o sujeito precisa inter-relacionar-se com a virtualidade. 
A EAD também faz parte das relações comerciais que, ao passo que pertencem ao repertório humano de busca de completude, de necessidade de aplacar a subjetividade inerente ao sujeito, afetam o modo como a sociedade interage entre si, no seu interior e na indução de constituição do sujeito do seu tempo. Logicamente, não poderia ser diferente com o ensino a distância que alavancou a conexões comerciais, numa sociedade de mercado que abarca o todo para suster suas demandas e fomentar ainda mais demandas, como diz respeito à subjetividade de um sujeito social carregado de incompletude. A incidência discursiva paira sobre o sujeito que enuncia e interage numa sociedade organizada. Maingueneau discorre 0 seguinte a esse respeito:

Toda operação de pensamento remete a um dispositivo de transmissão que o estrutura a partir do interior e do qual não pode ser dissociada. É preciso, consequentemente, interessar-se por estes "processos de organização", pensar a instituição não como um organograma estático, mas como um complexo que também inclui gestos e modos de relação entre os homens. A ideologia não deve ser concebida como "visão de mundo", mas como modo de organização, legível sobre as duas vertentes da prática discursiva (MAINGUENEAU, 1989, p.60).

O sujeito social, atravessado pela ideologia, se apropria da formação discursiva. No caso da formação discursiva que envolve o cenário da EAD, o sujeito é levado a interagir com o mundo do qual faz parte para atender às demandas de mercado, de uma sociedade organizada nos moldes capitalistas, em que é preciso trabalhar para sobreviver e, ao mesmo tempo, obter formação profissional para competir e galgar uma posição nesse mercado.

Por analogia, tem-se uma engrenagem que não para, e que exige que o sujeito mantenha-se em movimento, preferencialmente, acompanhando o mesmo ritmo acelerado das demandas. O que emerge dessas relações é, exatamente, o fato de o sujeito transpor sua subjetividade no trabalho, no trato profissional de produzir e formar-se, num ciclo sem fim, como o é a sua busca pela completude. O ensejo de toda uma simbologia permite o sujeito ser e se estabelecer, como bem é possível constatar nas palavras de Lacan:

Quer dizer que, na relação do imaginário e do real, e na constituição do mundo tal como ela resulta disso, tudo depende da situação do sujeito. E a situação do sujeito [...] é essencialmente caracterizada pelo seu lugar no mundo simbólico, ou, em outros termos, no mundo da palavra (LACAN, 1994, p. 97).

O sujeito depende do imaginário e do real que o contorna no mundo, e o coloca em condições de produção que o interpelam e que o conduzem para a interação nas esferas do universo simbólico, pois, as relações humanas acontecem no plano do simbólico. Por isso, a maneira como a sociedade se organiza provoca e faz emergir incompletudes nos sujeitos que convivem entre si, que marcam e são mutualmente demarcados pelo meio, pelas formações sociais, discursivas e ideológicas que os interpelam em sujeitos da língua e da história.

De uma vida de relações concretas, em que interação se dava pessoalmente, passouse para uma vida híbrida, em que o ser humano convive tanto no concreto quanto no virtual, e essas formas de interagir incorrem uma sobre a outra, dito de outro modo, uma influencia e complementa a outra. O mundo cibernético ocorre em paralelo à vida prática, e as relações humanas acontecem naturalmente, onde o sujeito é atravessado pelas formações discursivas que incidem sobre o lugar social por ele ocupado tanto no virtual quanto na sua vida concreta. Não há como separar o sujeito virtual do sujeito concreto, apesar das condições de produção discursivas serem distintas, uma na vida concreta outra na vida virtual, ambas alocam o sujeito numa posição social que, por meio do seu discurso ou do seu dizer, dará evidências da ideologia 


\section{$=$ TRAMA $=$}

que o atravessa, que o interpela. Para uma compreensão do que está intrincado na relação sujeito/ideologia, leia-se:

IDEOLOGIA: elemento determinante do sentido que está presente no interior do discurso e que, ao mesmo tempo, se reflete na exterioridade, a ideologia não é algo exterior ao discurso, mas sim constitutiva da prática discursiva. Entendida como efeito da relação entre sujeito e linguagem, a ideologia não é consciente, mas está presente em toda manifestação do sujeito, permitindo sua identificação com a formação discursiva que o domina. Tanto a crença do sujeito de que possui o domínio de seu discurso, quanto a ilusão de que o sentido já existe como tal, são efeitos ideológicos (FERREIRA, 2001, p. 17 - 18).

A configuração da educação a distância forma sujeitos profissionais na esfera digital para atuarem tanto no virtual quanto nas relações concretas da sociedade humana. Todo sujeito que nasce na era digital é assujeitado por ela, inserido nas condições de produção que estão fazendo o mundo atual acontecer. No que diz respeito à relação com o aprender, o que se tem é um dinamismo diferente do tradicional, o fato é que houve uma ampliação nas formas de aquisição de aprendizagens, se utilizando de canais da era digital para promover experiências com o conhecimento.

Inferir juízo de valor quanto a EAD ser boa ou ruim para a sociedade, não vem ao caso, visto que o sujeito atual acaba por manter-se à margem, ou seja, sem condições de interação caso não domine os mecanismos de fruição do sistema globalizado. Isso inclui o ensino a distância, que já está se inclinando, pelo menos parcialmente, para a maior parte das categorias de formação intelectual, técnica-profissional e de capacitação de uma considerável parcela da população de estudantes.

A EAD só é possível devido à tecnologia, que passa a ser um meio, não um fim. De qualquer modo, são as novas tecnologias que surgem que impulsionam e ampliam as oportunidades de ensino a distância. Com isso, a EAD cumpre o papel de levar educação para áreas remotas e cidades que não têm universidades, por exemplo, o que propicia um ganho de qualificação profissional num âmbito mais democrático. Além da flexibilidade de horários de estudos para o sujeito participante da EAD, permitindo que se concilie trabalho, estudos e vida pessoal mais equilibradamente.

O sujeito é assujeitado para poder interagir, para pertencer, e no caso do ensino a distância, não há como retroceder aos métodos de ensino tradicionais, pois, sujeitos da era digital precisam se apropriar da formação discursiva do mundo atual. Neste viés, está a EAD que, paulatinamente, se apodera dos espaços de aprendizagens e traz o sujeito para as suas condições de produção, na sua formatação, da qual é possível ponderar o seguinte: o sujeito da $E A D$, veementemente inserido nessa posição de sujeito usuário/aluno de ensino a distância, passa a ter que prezar pela disciplina e autonomia, caso contrário, entende-se que não se inscreveu, de fato, na formação discursiva do ensino a distância e, tampouco, compreendeu as condições de produção desta modalidade que exige uma nova relação com o aprender. Na citação que segue, Orlandi assevera acerca das condições de produção:

As condições de produção implicam o que é material (a língua sujeita a equívoco e a historicidade), o que é institucional (a formação social, em sua ordem) e o mecanismo imaginário. Esse mecanismo produz imagens dos sujeitos, assim como do objeto do discurso, dentro de uma conjuntura sócio-histórica. [...] É pois todo um jogo imaginário que preside a troca de palavras (ORLANDI, 2009, p. 40).

O jogo imaginário que envolve a EAD e a relação com o sujeito que se insere na conjuntura sócio histórica da era digital ficam suscetíveis às condições de produção do meio 
virtual, num jogo de palavras que permeiam esse universo, repleto de termos próprios dessa realidade cibernética. Assim, um perfil criado na rede é, em essência, a inscrição do sujeito na formação discursiva da cibercultura, em se tratando de educação a distância, a posição sujeito, ou seja, o modo como se comporta, o dizer que se utiliza, se dá enquanto aluno digital que já está na ordem do discurso da internet e suas interpelações.

Muitas instituições educacionais aderiram ou ainda incorporarão ao chamado ensino híbrido, que mescla a EAD com um percentual de carga horária presencial. Como se tem apontado, especialmente, para o novo formato do ensino médio, o que carece olhar para o novo sujeito que já transita na formação social da era da internet, em condições de produção propensas aos desenvoltos processos interativos de construção de sentido no ambiente digital. O encadeamento dos acontecimentos do humano e as transposições discursivas que despontam no sujeito perpassam o que se pode chamar de real, como define Pêcheux:

Supor que, pelo menos em certas circunstâncias, há independência do objeto face a qualquer discurso feito a seu respeito, significa colocar que, no interior do que se apresenta como o universo físico-humano (coisas, seres vivos, pessoas, acontecimentos, processos...), 'há real', isto é, pontos de impossível, determinando aquilo que não pode não ser "assim". (O real é o impossível... que seja de outro modo) (PÊCHEUX, 2008, p. 29).

O real tido como algo inacessivel para o ser humano, segundo a teoria apresentada acima em que reflete sobre a impossibilidade de materializar discursivamente a realidade, perde alcance ao ser simbolizado por qualquer forma ou tentativa de representação. Com isso, entende-se que o sujeito fica a deriva do real, mas nunca o retém simbolicamente, o que não compromete suas possibilidades de inserção nas formações discursivas e atravessamentos ideológicos. Em suma, o sujeito está sempre sendo interpelado e aludido pelas condições de produção de sua subjugação que determina o sujeito às especificidades da formação discursiva e ideológica que se inscreveu no processo de identificação.

Qual o perfil do sujeito da EAD? Trata-se de um sujeito que está alinhado com as condições de produção da era digital, que promove em si um tino autodidata, pesquisador e leitor assíduo, que se empenha em criar as próprias estratégias de aprendizado, partindo do pressuposto do autoconhecimento. É o sujeito interessado no formato de flexibilização de estudo, e que sabe gerir o próprio tempo com a finalidade de otimiza-lo e cumprir com prazos e demandas pré-estabelecidas na EAD.

Diferentemente do discurso popular de que o ensino a distância é inferior ao ensino presencial, o fator determinante, em ambas as categorias de educação, é sempre o sujeito e a sua interação com o conhecimento que está diante de si. Em outras palavras, é o sujeito, em suas condições de produção, que definirá a qualidade dos seus resultados na intensidade de filiação discursiva da área estudada.

É uma questão de apropriação do saber virtual, de suas tecnologias e de aprender a aprender mediante o quadro de constantes mudanças e desafios do mundo on-line. Para tanto, o sujeito necessariamente já é assujeitado, já tem o seu dizer representando uma formação discursiva, com a ideologia do universo de conectados atravessando e designando o seu discurso como modo de ser e agir.

Embora o sujeito busque pelo ímpeto de ser o dono do seu dizer, para viver em sociedade e interagir com o mundo, terá sempre que estar inscrito em uma formação discursiva, isto é, falará sempre de uma posição social, dentro de determinadas condições de produção. O que acontece com a cibercultura, em que milhares de pessoas estão inseridas, ou filiadas, ao modo de ser e agir dessa realidade. O que denota é que o sujeito adentra na simbolização, 
no discurso, na sua fala a partir do mundo que o cerca, de algum modo, para deixar que sua vida flua, para pertencer e passar a figurar aos moldes daquilo que o assujeita. Pêcheux elucida a relação discurso, sujeito e história:

Não há, pois, discurso, realmente falado por seres humanos, que possa se destacar completamente dos trás-mundos (ou dos pré-mundos) que o habitam [...] Portanto, se no espaço revolucionário tem-se a questão da passagem de um mundo a outro, a relação com o invisível é aí inevitavelmente colocada, do mesmo modo como nas formas históricas da contrarrevolução: o conjunto constitui um só processo, contraditório, no qual se tramam as relações entre língua e história (PÊCHEUX, 1990, p. 9).

No curso histórico da humanidade o discurso e toda a simbologia que emana do ser humano, que ao mesmo tempo afeta e é afetado exatamente no plano da língua e história para a constituição do sujeito, o que envolve a crescente tecnologia que não tem como retroceder pelo fato de contribuir para uma fruição de possibilidades profissional. Isso posto, a EAD já constitui a sociedade desse tempo, e cada vez mais adentra em esferas antes não cogitadas para o ensino a distância, influencia e é influenciada pelos sujeitos e todo o processo se estabelece tendo a língua como o meio de principal de conceber as relações, que se expande nos algoritmos que também passam a significar nas condições de produção virtuais.

A alta evasão de alunos no sistema EAD se dá quando o sujeito não se filiou devidamente na formação discursiva do ensino a distância, isto é, não se moldou às preeminências da relação com o aprender autônomo. Apesar de todo o aparato tecnológico e de conexão como, por exemplo, a chamada plataforma moodle, o sujeito/usuário/aluno que não buscar dominar mecanismos de navegação on-line e manter-se aberto para as inovações que ocorrem velozmente, ou, o sujeito que não se identificar com todo o universo que envolve a EAD experimentará um fenômeno de contra identificação com formação discursiva e com a formação ideológica, passando a não ter condições de construir significados ou de aferir efeitos de sentidos no universo da virtualidade.

Para produzir efeitos de sentido em um mundo em que a internet rege boa parte das relações humanas, pessoais e profissionais, é inevitável que se leve em conta as condições de produção, ou seja, o lugar de onde os sujeitos interagem. No tocante aos mecanismos de produção de sentido e como o discurso significa de acordo com a conjuntura de sua ocorrência, Orlandi assevera:

Os efeitos de sentido são produzidos por mecanismos tais como o dos registros, o dos tipos de discurso sem esquecer o fato de que o lugar dos interlocutores significa. Essa é uma especificidade: nas marcas de interlocução - em que os sujeitos falam de seus lugares - há vestígios da relação entre a formação discursiva e a formação ideológica (ORLANDI, 1996, p. 121).

Essa interlocução dos sujeitos, tratada neste artigo a despeito da modalidade EAD, ocorre entre a própria formatação da plataforma de acesso, ou ambientes que simulem uma sala de aula on-line, os professores-tutores envolvidos na promoção dos usuários/alunos e os sujeitos que se filiam, todos os participantes construirão significados na relação que estabelecerem no ensino a distância. De algum modo, por simbologia e/ou acordos linguísticos compartilhados entre as partes (os sujeitos) da EAD, cada um falando do seu lugar social, da sua posição sujeito, com seus atravessamentos ideológicos. Onde cada formação discursiva autoriza o dizer, o discurso do sujeito, fazendo emanar das e nas relações humanas, que acontecem mediante toda a complexidade que envolve os sujeitos e suas condições de produção, as quais determinam o discurso e, em consequência, a vida que se leva. 
Do sujeito concreto, isto é, a pessoa física, para o sujeito on-line, a pessoa na interação virtual. O que faz o sujeito ser quem ele é? Tudo o que constitui o sujeito perpassa a sua língua e a sua história, além da própria subjetividade que o irrompe a ser. Na relação com o meio e com outros sujeitos é que se forma o sujeito, é o que vem antes do sujeito, o que lhe é externo, mas também o que lhe é interno que configura seu modo de ser e agir. O humano está sujeito às condições de produção do discurso, num âmbito em que tudo já é dado ao nascer, e no decorrer da vida, numa dinâmica entre afetar e ser afetado, englobando fatores internos e externos ao sujeito que o condiciona numa dada posição social que produz determinado discurso. No universo on-line o sujeito passou a ser, inferir sentido, e estabelecer significados, numa relação híbrida entre o sujeito da vida concreta (palpável, dos sentidos) e a virtualidade das coisas, do mundo e de si mesmo. Pêcheux relata essa complexidade que forma o sujeito:

O que precisa ser compreendido é como os agentes deste sistema reconhecem eles próprios seu lugar sem terem recebido formalmente uma ordem, ou mesmo sem 'saber' que têm um lugar definido no sistema de produção. Quando alguém se vê obrigado a ocupar um lugar dentro de um sistema de trabalho, este processo já se deu anteriormente; tal pessoa sabe, por exemplo, que é um trabalhador e sabe o que tudo isto implica. O mesmo acontece quando alguém é, por exemplo, nomeado juiz. O processo pelo qual os agentes são colocados em seu lugar é apagado; não vemos senão as aparências externas e as consequências. Para compreender como este processo se situa em um mesmo movimento, ao mesmo tempo realizado e mascarado, e o papel que nele desempenha a linguagem, devemos renunciar à concepção de linguagem como instrumento de comunicação. Isto não quer dizer que a linguagem não serve para comunicar, mas sim que este aspecto é somente a parte emersa do iceberg (PÊCHEUX, 1997, p. 26).

Conforme o exposto, todo o processo de ser do sujeito acontece no âmbito da língua, por meio do que o simboliza, se estabelece sem que ele perceba, como de modo automático é, faz e fala a partir de um lugar pré-estabelecido, que o nomeia, que o designa, acomodando-o em dada formação discursiva, com os devidos atravessamentos ideológicos. Não tem como não o ser, pois, na identificação com determinada formação discursiva os efeitos da interpelação ideológica estão latentes.

$\mathrm{Na}$ alusão ao iceberg, dada por Pêcheux, o que constitui o sujeito é muito mais do que o aparente - o discurso -, trata-se do emaranhado de subjetividade, língua e história que o constitui e reconstitui num dinamismo de afetos, hora o sujeito é afetado pelo externo, hora o ele afeta a si mesmo e ao que Ihe extrapola a existência. Deste modo, é o lugar social do sujeito que vai fornecer, natural e automaticamente, os ensejos para a sua atuação e o seu dizer social, implicando na produção e reprodução de ideologia.

No que tange aos modelos tradicionais de ensino vistos até então estão, como tudo, à mercê da mudança. A EAD incorpora estratégias flexíveis de lidar com a educação, alinhadas com as especificidades dos sujeitos contemporâneos que, por sua vez, estão suscetíveis ao modo de ser e agir de uma sociedade organizada também na esfera virtual. Portanto, há uma duplicidade de interação social por parte do sujeito, a qual compreende no fato de ele pertencer à confluência entre a virtualidade e o mundo concreto das coisas físicas, que se fundem e se complementam entre si, resultando na constituição do sujeito.

Sabe-se que o ser humano atual é a consequência das experiências de viver em um mundo de mudanças repentinas, assim, também são as metodologias e modalidades de ensino que tendem a ser consonantes às necessidades e anseios do sujeito e suas demandas. Ou seja, o modo de apropriação do conhecimento acompanha a fluidez do sujeito que, nos dias de hoje, 
está inserido na formação discursiva do universo conectado - repleto de atravessamentos ideológicos da esfera virtual e da complexidade inerente ao ser humano.

Não compreender o ensino a distância ou, ao menos, não ter a noção do que implica fazer parte da formação discursiva do EAD, coloca o sujeito à margem da própria sociedade que o constitui, mas que, paradoxalmente, o exclui quando ele não se inscreve na formação discursiva da vida em rede ou como partícipe de uma posição-sujeito interpelado pela formação social de um núcleo de proposições cibernéticas. Dito de outro modo, compreender e interagir com a educação a distância passa a ser pré-requisito dos sujeitos contemporâneos para ser e agir no universo on-line que permeia a sociedade que se tem hoje.

\section{CONSIDERAÇÕES FINAIS}

Neste artigo, intitulado "EAD: um caminho sem volta", o compromisso se manteve em mostrar como o sujeito do seu tempo está à deriva das organizações sociais, em como a língua, a subjetividade e a história acomete sobre cada pessoa. Diante do cenário cibernético, onde as relações humanas se expandiram e passaram a mediar questões como educação e formação profissional, por exemplo, compreende-se que o sujeito contemporâneo não pode negar a proeminência do ensino a distância em sua interação com o mundo circundante.

Para realizar a análise e suscitar as reflexões neste trabalho, utilizou-se da teoria da Análise do Discurso, de linha francesa, que embasou toda a elucidação do fato que o sujeito circunscreve a sua existência ao filiar-se em determinada formação discursiva, que é atravessada por ideologia e que permite ao sujeito afetar e ser afetado pelo modo como a sociedade se estabelece. Atualmente, ser e agir no mundo virtual exige do sujeito uma duplicidade entre concreto e abstrato, numa relação entre o real e o simbólico dos sujeitos e das coisas que há. Inerente ao universo on-line está o sujeito que coexiste e, como num mundo paralelo e ao mesmo tempo fundido com a realidade concreta das coisas, o sujeito infere sobre o mundo, ao passo que também é resultado da sua língua, sua subjetividade e sua história.

Ainda que existam prós e contras cerceando a EAD, é necessário lapidar estratégias e atentar para o dever de adequação por parte do sujeito/usuário/aluno como aquele que está inscrito numa formação social, e que assume uma posição-sujeito que está disposto ser autônomo, negá-la seria posicionar-se aquém da realidade de uma cibercultura. Ora, com o ritmo frenético de uma sociedade produtiva que desencadeia as questões da subjetividade e incessante necessidade de completude no transcorrer das relações de mercado, em processos infindos de competitividades oriundos pulsão no mercado de trabalho, nada melhor do que deixar-se fluir na conjuntura virtual dos sujeitos e das coisas desse tempo.

Finalmente, a internet é reconhecida como a grande revolução que mudou a relação entre os sujeitos e a sociedade como um todo. Agora, o mundo globalizado cria condições de produção que envolve os sujeitos numa ampla rede de relações dinâmicas e de obtenção de conhecimento no universo virtual, sendo a EAD uma modalidade de ensino de significativa conexão com o sujeito de seu tempo. Ademais, o elo entre a língua, a subjetividade e a história concebe a formação discursiva e os atravessamentos ideológicos que culminam na fluidez do sujeito atual.

\section{REFERÊNCIAS}

FERREIRA, Maria Cristina Leandro (Orient.). Glossário de termos do discurso: projeto de pesquisa: A

Aventura do texto na perspectiva da teoria do discurso: a posição do leitor-autor (1997-2001)/Orientadora:

Maria Cristina Leandro Ferreira; Bolsista de Iniciação Científica Ana Boff de Godoy... [et al.]. - Porto Alegre:

UFRGS. Instituto de Letras, 2001. - 30 p. 
LACAN, Jacques. O seminário. O estádio do espelho como formador da função do eu [1949]. In: Escritos. Tradução de Vera Ribeiro. Rio de Janeiro: Jorge Zahar Editor, 1998. Livro 1: os escritos técnicos de Freud. Rio de Janeiro: Jorge Zahar, 1994.

LÉVY, Pierre. Cibercultura. São Paulo: Editora 34, 1999.

MAINGUENEAU, Dominique. Novas tendências em análise do discurso/ D. Maingueneau; tradução Freda Indursky; revisão dos originais da tradução Solange Maria Ledda Gallo, Maria da Glória de Deus Vieira de Moraes. - Campinas, SP: Pontes: Editora da Universidade Estadual de Campinas, 1989.

ORLANDI, Eni P. A Linguagem e seu funcionamento: as formas do discurso, Eni P. Orlandi - $4^{\text {a }}$ Edição, Campinas, SP: Pontes, 1996.

2009.

Análise do Discurso: princípios e procedimentos, Eni P. Orlandi - 8a Edição, Campinas, SP: Pontes,

PÊCHEUX, Michel. Delimitações, inversões, deslocamentos. (Trad. José Horta Nunes). Cadernos de Estudos Linguísticos, Campinas, São Paulo, n. 19, p. 7-24, jul,/dez/1990.

O Discurso: estrutura ou acontecimento, Michel Pêcheux; tradução Eni P. Orlandi - $5^{a}$ Edição,

Campinas, SP: Pontes Editores, 2008.

Semântica e Discurso: uma crítica à afirmação do óbvio. Trad. Eni Pulcinelli Orlandi [et.al.] - 2.ed. Campinas, SP: Editora da UNICAMP, 1995.

Semântica e discurso: uma crítica à afirmação do óbvio. Trad. Eni Pulcinelli Orlandi [et.al.] - 2.ed. Campinas, SP: Editora da UNICAMP, 1997. 